\title{
Exploratory Factor Analysis of The Underlying Structure of Talent Management Practices Among Universities in Uganda
}

\author{
Miiro Farooq $q^{a, *}$ \\ aslamic University in Uganda \\ *Corresponding author: miirofarooq@gmail.com
}

\section{Article history}

Received: 2017-06-22

Received in revised form: 2017-11-02

Accepted: 2017-11-05

\begin{abstract}
The empirical study presents the findings generated from 300 randomly selected respondednts from six universities in the central region of Uganda. The survey tool contained 24 self-reported items with a five point Likert measuring scale chosen from the earlier studies done on the four sub-dimension of talent management construct. Exploratory Factor Analysis was used with Promax rotation to establish whether identification, development, culture and retention are true dimensions of talent management construct. The results from the date exhibited that the four factors of talent management structure were explained at $56.1 \%$ variance. The validity and reliability were sound enough since the internal consistency scale estimates ranged from 0.837 (identification), 0.7 (development), 0.707 (culture) and 0.758 (retention) for the factor structure extracted. Lastly, the findings gave plausible empirical evidence for the validity of the four sub-dimensions and their individual items.
\end{abstract}

Keywords: Talent management, identification, development, culture, retention, university performance, exploratory factor analysis 


\subsection{Introduction}

Managing talent has become a challenging issue among organizations in all fields that contribute to the development of the world. This challenge of talent management has been brought about by the fact that human capital has become so sensitive, privy and fragile in the management of organizational business strategy. The process of recruitment, assessment, development, management and maintenance of the most resourceful and important people in the organization needs to be very clear and focused on the objective of human resources in that staff's roles are zhould be stated well to avoid collusions and boredom while at work place (Khatri et al., 2010). It is also important to worth noting that for businesses to be successful today in any field, its structures and systems should tender in an element of handling employees with care such that attention and focus are won towards serving the organization diligently and committedly. And this can due to that fact that these human resources are the engine that ignites the way decisions are made and driven them towards organizational success (Rachel, Pavithra \& Imran, 2016).

\subsection{Definition of Talent Management}

The term talent management is the prediction and anticipation of the needed skilled human resources for improving an organization's performance levels to address the needs of its customers (Khatri et al., 2010). Talent management may also be referred to as a philosophy for management science whose sole aim is to provide strategic resourceful personnel for value addition and successful planning in order to meet the organizational goals and objectives (Rachel, Pavithra \& Imran, 2016). It involves the processes of identification, recruitment, development and retention with purpose of strengthening the available workforce and avoiding vacuum that may deter smooth progress and development of an organizations agenda (Miiro et al., 2016). Besides, since talent management is an important aspect in the management of business strategy in an organization, it is imperative to link both the daily organizational strategy and needs in the sense that succession planning, employee development and assessment are given priority for preparation of future leadership for an organization sustainable progress and development (Mazurkiewicz, 2014). Nevertheless, since there is no agreed upon definition of talent management, so far the availbale theories and models agree that talent management practice is embedded with features of employee identification, recruitment development and retention (Rachel, Pavithra \& Imran, 2016). Therefore succession planning strategy of an organization should include identification and development of potential employees with the purpose of retaining them so as to enhance leadership development and proper achievement of organizational agendas.

In the context of higher education some institutions have embarked on the strategy of talent management practices. However, there are still some challenges varying from one institution to another. For example in a study done in Botswana on implementation of talent management strategies in higher education by Rudhumbu (2014), it was found that dedication to talent management practices was in progress though people had scanty knowledge and ability to implement this strategy. Also, Bradley (2016) states that in the UK and Australia, universities are given autonomy to function properly in the gradually deregulated knowledge economy with the aim of establishing the proper framework through which universities can manage to transform their performance levels and at the same time thrive in the transactional talent management system. Even though universities are normally fragmented with focus on individual performance loosely, they should put in place an enabling environment to motivate workers towards job 
satisfaction, commitment, career development and training for knowledge and skills acquisition and provide incentives so as to increase their levels of productivity, quality of services, accomplishment of goals, employee commitment and reduction of turnover rates (Barkhuizen, Mogwere \& Schutte, 2014a; Rachel, Pavithra \& Imran, 2016). Furthermore, institutions should integrate technological means to ease the work of both the administrative and teaching staff such that traditional ways of operation are eliminated in order to avoid frustration of workers with mechanical ways of executing duties (Khatri et al., 2010; Mazurkiewicz, 2014; Trayek et al., 2016).

In this era, universities are vying with one another against talent shortage. This has not only resulted into moonlighting and shortage of qualified staff but also led to recruitmrnt of incompetent staff in some universities especially in Africa. In order for universities to combat these challenges, they should employ the marketable strategies of employee satisfaction. Sonia \& Krishnan (2015) reveal that university leadership should focus more on salary improvement, availability of benefits, imitation of ongoing research grants, provision of enabling environment and employment of partner and spouse since these are the main challenges that make employees' retention and movement unavoidable. Moreover, Rudhumbu (2014b) opines that higher education insititutions (HEIs) in some parts of the world have failed to compete favorably due to fear of taking risks and investing in talent management and development. This is coupled with challenges that range from lack of knowledge and not streamlining policies that govern human resource management. Meanwhile, talent is a war that comes up due to lack of knowledge and practice, thus educational institutions should get involved in the war and occupy its frontline such that tools and means of scooping and developing unique human resources for survival their institutions are put in place to make universities more of places of innovation, transparent and efficient service delivery (Sonia, Krishnan, \& Joseph, 2015).

In addition, the topmost role of any chief executive officer (CEO) today is to have a strategy for expansion of his organization in the corporate world. In the same vein, university leadership today face the same challenges to the extent of failing to retain the developed staff. It is therefore, imperious that firm practical solutions be put in place to address this macabre especially in developing world (Chandrachud \& Athavale, 2015). Consequently there is an urgent need to accept the challenge, lay the strategy and copy what developed countries like Germany and USA did in order to save the image of their institutions and at the same time also compete favorably in terms of expansion, knowledge creation and development (Chandrachud \& Athavale, 2015; Miiro et al., 2016). Due to turbulent moments that some universities are going through, there is scanty and anecdotal studies on this. Thus it is partly against this backbground that the current study was designed to unpack the underlying factors of talent management practices among univeristies in Uganda. Moreover, some studies elsewhere found out that universities wre faced with challenges of shortage, qualified and comptent staff to implement strategic plans (Bradley, 2016; Sonia \& Krishnan, 2015), Lack of knowledge and policy guideline to implement the strategy (Khatri et al., 2010; Lis, 2013; Mazurkiewicz, 2014; Rudhumbu, 2014a), and others were not even aware that succession plan and university strategic plan are both linked to talent management practices(Barkhuizen, Mogwere \& Schutte, 2014b; Miiro et al., 2016). Literature suggests that they are many factors for defining talent management construct. However, this study sought to establish whether identification, development, culture and retention are the true underlying factors that are used to measure talent management practices in Ugandan universities. 


\subsection{Objective of The Study}

The objective of the study was twofold. First was to establish the fundamental factors that explain the structure of talent management among universities in the central region of Uganda; the second was to establish the validity of the talent management construct measurement scale in reference to the data obtained.

\subsection{Methodology}

\subsection{Sample Size}

This empirical quantitative study was a cross sectional survey that employed 300 randomly chosen respondents from six universities in the central of Uganda. The demographic factors of respondents included gender, working experience, position and education levels. Meanwhile, gender in terms of male staff contributed 59.3\% $(\mathrm{n}=178)$ to sample size and the females were $40.7 \%(\mathrm{n}=122)$. Yet, staff position contained lecturers with 53\% $(\mathrm{n}=159)$, administrators were $30.7(\mathrm{n}=92)$ and those that occupied both position of administrator and academic staff were $16.3 \%(n=49)$. Education levels ranged from bachelor's degree with a percentage of 27.3( $n=82)$, master's degree were 58.3\% ( $\mathrm{n}=175)$, while those with $\mathrm{PhD}$ were $14.3 \%(\mathrm{n}=43)$.

\subsection{Instrumentation}

The data of the study were collected using a survey tool adopted and adapted from previous studies. The survey questionnaire had two parts that required the respondent to answer. They included the demographic details and the levels of their perceptions towards talent management practices and its structure. A total of 24 items was used to solicit data for the four dimensions of talent management construct which included, identification (7 items) development (5 items), culture (5 items) and retention (5 items). The items were drawn from Annakis, Dass \& Isa (2014), and Oehley $(2007,2013)$. A five point Likert scale was used ranging from strongly agree to strongly disagree. To validate the content before data collection, the survey tool was examined by the experts from both the fields of reseach and management studies. Some of the items were redefined basing on the advice of the experts to fit the interest of the study before data collection.

\subsection{Data Collection And Analysis}

After securing a letter of acceptance from Uganda National Council for Science and Technology (UNCST) to collect data from the universities, the researcher still obtained permission from individual universities so as to seek for staff's participation in the study. With the help of research assistants and volunteers from the university staff, 577 questionnaires were distributed across universities in the central region. Out of them, 350 were returned and subjected to data scrutiny and cleaning. Moreover, 300 emerged useful for further analysis. Exploratory factor analysis as a robust technique for extracting the underlying factors for talent management construct was employed.

Equally the technique was used to establish the correlation among the factors that determine talent management construct. Exploratory factor analysis (EFA) techniques is known for identifying the structure of factors that measure a set of variables that make up the model (Coughlin, 2013; Ngure, Kihoro \& Waititu, 2015). In addition, EFA was plausible for use since it addressed the purpose of the research. Promax rotation was employed due to the eagerness 
establishing whether that the subdimension of the construct are correlated (Baglin, 2014; Matsunaga, 2011; Wiktorowicz, 2016).

\section{$5.1 \quad$ Results}

\subsection{Underlying Dimensions of Talent Management Construct}

The study followed the procedure of PAF analysis and the results of the study obtained from the data proved that the sample was adequate for inter-item correlation. Also, the Kaiser-MeyarOlkin (KMO) proved that the sample was adequate with score values (0.886) above the threshold of 0.7. The Bartlett's test of sphericity showed that the tests of correlation matrix was significant at chi-square value $\left(\chi^{2}=2066.737\right) \mathrm{df}(171)$ and $\mathrm{p}(0.000)$. These values indicated that the overall correlation in terms of correlation matrix was reasonable. In summary, the factorability of the data from the results of the study was observed and hence justifying the application of PAF technique analysis.

In addition, the results from the Scree plot (figure 1) supported the proof that the items they are only four underlying factors of talent management construct. Meanwhile, the Eigen value and the total variance explained with $(56.1 \%)$ were also supportive of the data findings of the study.

\section{Figure 1 Scree plot}

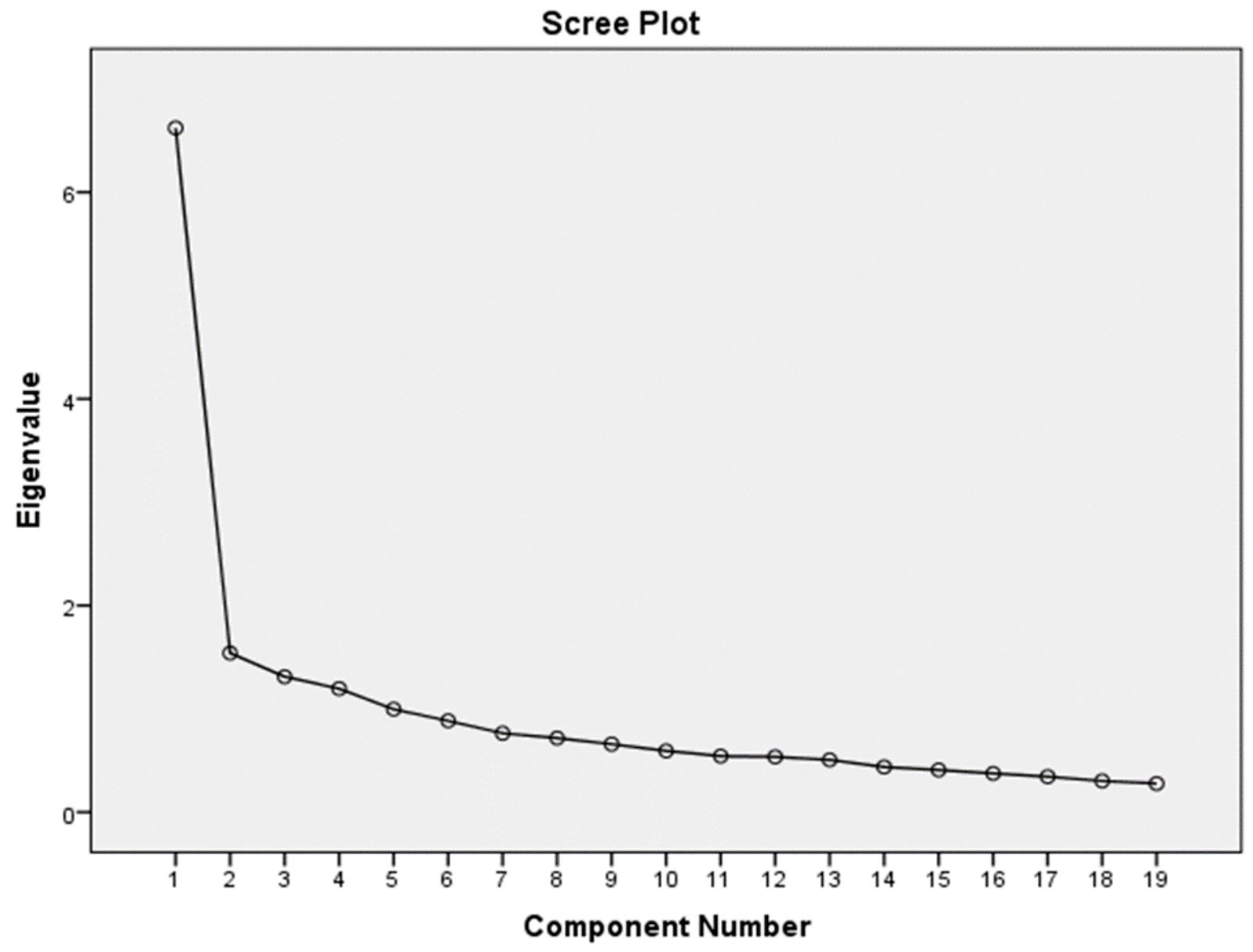

Equally, an assessment was done on eigenvalue procedure and reflected that it was greater than 1.0, hence showing the existence of four dimensions that were explained at $56.1 \%$ 
total variance without cross loading. In the table of communalities, the correlation among the factors was significant and the score ranged values from 0.313 to 0.675 .

In addition, the results of study showed that out of 24 items only 17 emerged relevant and were based on the loading levels. Talent identification exhibited five items with loading that ranged from 0.680 to 0.714 . Talent development comprised of four items with score of between 0.531 to 0.794 . Talent culture consisted of three items with a score ranging from loading from 0.632 to 0.812 , and lastly talent retention was assigned five items with loading between 0.455 to 0.788 .

It is therefore important to observe that the four dimensions of talent management construct (identification, development, culture and retention) were above the maximum cut off for the factor loading since each of them obtained loading weights above 0.5. Moreover, there was no cross loading among dimensions. The evidence for availability of the four factor loadings with their respective items, eigenvalue, total variance explained for each and communalities are indicated in the table 1.

Table 1: Factor Loadings, eigenvalue, total variance explained and communalities of the four dimensions of the talent management construct

\begin{tabular}{|c|c|c|c|c|}
\hline Factor and item & $\begin{array}{l}\text { Factor } \\
\text { loading }\end{array}$ & Eigenvalue & $\begin{array}{c}\text { Total } \\
\text { variance } \\
\text { explained }\end{array}$ & Communalities \\
\hline Identification & & 6.6 & $34.8 \%$ & \\
\hline $\begin{array}{l}\text { Human resource manager addresses } \\
\text { my performance in a timely way } \\
\text { without letting poor performance } \\
\text { continue. }\end{array}$ & 0.680 & & & 0.61 \\
\hline $\begin{array}{l}\text { University leadership adjust } \\
\text { managerial decisions and actions to be } \\
\text { appropriate with my performance } \\
\text { level. }\end{array}$ & 0.741 & & & 0.66 \\
\hline $\begin{array}{l}\text { My university leadership is aware of } \\
\text { my performance level and ability } \\
\text { towards transformation. }\end{array}$ & 0.748 & & & 0.63 \\
\hline $\begin{array}{l}\text { The university is always on the } \\
\text { lookout for talent people to occupy } \\
\text { important positions. }\end{array}$ & 0.864 & & & 0.67 \\
\hline $\begin{array}{l}\text { I am aware of the university's } \\
\text { systematic approach towards } \\
\text { identification and attraction high } \\
\text { potential staff for employment. }\end{array}$ & 0.741 & & & 0.60 \\
\hline Talent Development & & 1.5 & $8.1 \%$ & \\
\hline $\begin{array}{l}\text { I have been provided with } \\
\text { opportunities for training as an } \\
\text { identified staff in leadership } \\
\text { development programs. }\end{array}$ & 0.740 & & & 0.47 \\
\hline $\begin{array}{l}\text { The university systems and structures } \\
\text { are dynamic towards staff } \\
\text { developmental opportunities for both } \\
\text { administrative and academic } \\
\text { subordinates. }\end{array}$ & 0.531 & & & 0.42 \\
\hline $\begin{array}{l}\text { My university leadership assessed my } \\
\text { individual career development needs. }\end{array}$ & 0.794 & & & 0.59 \\
\hline
\end{tabular}


University leadership possesses a

0.758

genuine interest to foster my learning and career development.

\section{Culture}

My colleagues and I have been rewarded by my university for being exemplary at work.

University administration provides verbal or written recognition for individual contribution where appropriate.

I have been given salary increment in accordance to level of career development and performance.

\section{Retention}

The university provided me with standardized job description and performance requirements to avoid boredom.

I have been motivated by the university leadership through use of the resources available, time $\&$ materials.

The university leadership communicates to staff the university common goal and agenda.

I feel to be part of the university, I therefore serve it diligently and committedly.

I am regularly acknowledged and recognized for my contribution as opposed to relying on formal/structured awards.

0.632
0.55

1.3

$6.8 \%$

1.1 $6.2 \%$

\subsection{Reliability}

To obtain the reliability estimates for each of the subconstructs and the entire structure of talent management from the data, Cronbach's alpha coefficient value was used with emphasis on the threshold 0.05 requirement for social science research as indicated in the table 2.

Table 2 shows the number of items for each subconstruct and Cronbach's alpha

\begin{tabular}{ccc}
\hline Factor & Number of items & Cronbach's alpha \\
\hline Talent identification & 5 & 0.837 \\
Talent development & 4 & 0.7 \\
Talent culture & 3 & 0.707 \\
Talent retention & 5 & 0.758 \\
Total & $\mathbf{1 7}$ & $\mathbf{0 . 8 8 1}$ \\
\hline
\end{tabular}

In conclusion, the findings of the study generated a reliable four multidimensions structure of talent management and supported the findings of the earlier studies for (Alnaqbi, 2011; Barkhuizen, Mogwere \& Schutte, 2014b; Brown, 2014; Campbell \& Smith, 2014; Darabi, Maleki \& Hajinabi, 2014; Frederick, 2014). These factors further provided the practical evidence in support of Al-Awamleh (2006), Ámundadóttir (2013), Frederick (2014), Muhammad (2014), 
and Stans (2012) who stated that talent management is a key tool towards organization efficient and effective performance. The study also established that talent management practices among universities are employed at a level of $56.1 \%$. Nevertheless, it is important to note that talent identification is a crucial aspect since it contributed $34.8 \%$ against others which imply that for the rest of the factors of the construct to be reasonable enough and yield good results the stage of staff identification plays a very important role in organizational performance (Acar, 2016; Annakis, Dass \& Isa, 2014; Cannon \& McGee, 2011; Davies \& Davies, 2010). Furthermore, talent development contributed $8.1 \%$ of the variance explained which implied that employees should be developed after recruitment such that they gain more knowledge, skills and experience towards enhancement of both personal and university effective performance.

Through the Use of EFA technique, the results reflected that the reliability scale of talent management construct structure, for items loading on each of the dimension was high. Hence giving categorical and logical meaning of the factors with cumulative total variance explained at $56.1 \%$. The implication from the study result is that the factors extracted from the data are the true successful underlying dimensions of talent management practices as perceived by staff among universities in the central region of Uganda. Therefore, it can be opined that the validity scale for measuring the construct is plausible enough to be used in the management of universities. Furthermore, the Cronbach's alpha value scores ranged between (0.7- 0.837) and these were high meaning that there was internal consistency in the scale. In a nutshell, the results of the study generated from the data reflected that validity and reliability of the survey questionnaire was reliable and valid. This research instrument can be backed up by further examination of talent management practices in other educational organizations since the study was limited to only universities moreover in the central region of Uganda.

\section{References}

Acar, P. (2016). Theoretical journey of talent management: egalitarian and elitist approach. Pressacademia, 3(3), 284-284. https://doi.org/10.17261/Pressacademia.2016321984.

Al-Awamleh, R. a. (2006). Developing Future Leaders: The contribution of Talent Management. Management, (June), 1-21.

Alnaqbi, W. (2011). the Relationship Between Human Resource Practices and Employee Retention in Public Organisations: an Explanatory Study Conducted in the United Arab Emirates. Edith Cowan University Research On Line.

Ámundadóttir, S. D. Á. (2013). Organizational Behavior and Talent Management, 1-84.

Annakis, D., Dass, M., \& Isa, A. (2014). Exploring Factors that Influence Talent Management Competency of Academics in Malaysian GLC's and Non-Government Universities. Journal of International Business and EconomicsOnline) Journal of International Business and Economics, 2(24), 163-185. https://doi.org/10.15640/jibe.v2n4a9

Baglin, J. (2014). Improving Your Exploratory Factor Analysis for Ordinal Data : A Demonstration Using FACTOR. Practical Assessment, Research \& Evaluation, 19(5), 1-14. https://doi.org/10.1146/annurev.psych.53.100901.135239

Barkhuizen, N., Mogwere, P., \& Schutte, N. (2014a). Talent Management, Work Engagement and Service Quality Orientation of Support Staff in a Higher Education Institution. Mediterranean Journal of Social Sciences, 5(4), 69-77. https://doi.org/10.5901/mjss.2014.v5n4p69

Barkhuizen, N., Mogwere, P., \& Schutte, N. (2014b). Talent Management, Work Engagement and Service Quality Orientation of Support Staff in a Higher Education Institution. Mediterranean Journal of Social Sciences, 5(4), 69-77. https://doi.org/10.5901/mjss.2014.v5n4p69

Page | 77 
Bradley, A. P. (2016). Talent management for universities. Australian Universities' Review, 58(1), 13-19.

Brown, L. M. (2014). A Proposed Talent Management Model for Leader-Managers in State-Owned Enterprises in China. International Journal of Human Resource Studies, 4(3), 198. https://doi.org/10.5296/ijhrs.v4i3.6011

Campbell, M., \& Smith, R. (2014). High-potential talent-A view from inside the leadership pipeline. Center for Createive Leadership (CCL), 1-34. Retrieved from http://scholar.google.ca.ezproxy.library.ubc.ca/scholar?as_q=\&as_epq=high+potential\&as_oq=emp loyee + employer+personnel+leader+leadership + manager + management + executive + organization $+\mathrm{bu}$ siness + company + job + work + develop + development + train + training\&as_eq $=\& a s \_o c c t=t$

Cannon, J. a., \& McGee, R. (2011). Talent Management and Succession Planning. The Chartered Institute of Personnel and Development, 213-224. Retrieved from http://www.cipd.co.uk/NR/rdonlyres/CC24FEF5-42CB-465B-906C5C6B6651AAA0/0/9781843983095_SC.pdf

Chandrachud, M., \& Athavale, S. (2015). Talent Management Practices in Higher Educational Institutions: German and USA Perspective. IOSR Journal of Business and ManagementVer. II, 17(12), 2319-7668. https://doi.org/10.9790/487X-171220106

Coughlin, K. B. (2013). An analysis of factor extraction strategies: A comparison of the relative strengths of principal axis, ordinary least squares, and maximum likelihood in research contexts that include both categorical and continuous variables. University of South Florida. Retrieved from www.scholarcommons.usf.edu/etd/4459

Darabi, O., Maleki, M. R., \& Hajinabi, K. (2014). The relationship of talent Management and the Efficacy of Superior and middle-based Managers of Therapeutically- Educational Hospitals of Kermanshah City, 3(Ii), 544-548.

Davies, B., \& Davies, B. J. (2010). Talent management in academies. International Journal of Educational Management, 24(5), 418-426. https://doi.org/10.1108/09513541011055983

Frederick, A. K. (2014). Assessing talent management as a tool for employee retention: A case study of Procredit Saving and Loans Limited Kumasi. https://doi.org/10.1017/CBO9781107415324.004

Khatri, P., Gupta, S., Gulati, K., \& Chauhan, S. (2010). Talent Management in HR. Journal of Management and Strategy, 1(1), 39-46. https://doi.org/10.5430/jms.v1n1p39

Lis, A. (2013). in Search of Positive Organizational Potential : The Case of Frauenthal Torun Automotive Company. Journal of Positive Management, 4(1), 22-37.

Matsunaga, M. (2011). How to factor-analyze your data right: Do’s, don'ts, and how-to's. International Journal of Psychological Research, 3(1), 97-110. https://doi.org/10.4090/juee.2008.v2n2.033040

Mazurkiewicz, A. (2014). Talent Management As a New Paradigm N Management Science. Journal of Positive Management, 5(3), 15-28.

Miiro F, Othman, A., Sahari, M., \& Burhan, M. (2016). a Measurement Model of Talent Management Practices Among University Staff in Central. Journal of Positive Management, 3-19.

Muhammad, M. (2014). Relationship Between Human Resource Practices On The Effectiveness Talent Management Programme Amongs Generation Y Dissertation Submitted to the Othman Yeop Abdullah Graduate School of Business, University Utara Malaysia, in Fulfillment of the Requireme, $8(1), 131$.

Ngure, J. N., Kihoro, J. M., \& Waititu, A. (2015). Principal Component and Principal Axis Factoring of Factors Associated with High Population in Urban Areas: A Case Study of Juja and Thika, Kenya. American Journal of Theoretical and Applied Statistics, 4(4), 258-263. https://doi.org/10.11648/j.ajtas.20150404.15

Oehley, A. M. (2007). The Deevelopment and Evaluation of a Partial Talent management Competency Model. Stellenbosch University.

Page | 78 
Oehley, A.-M. (2013). The Development and Evaluation of a Partial Talent Management Competency Model. Journal of Chemical Information and Modeling, 53(December), 1689-1699. https://doi.org/10.1017/CBO9781107415324.004

Rachel, D. L., Pavithra, N. R., \& Imran, S. M. (2016). Impact of Talent Management on Organisation Culture. The International Journal Of Business \& Management, 4(2), 98 -102. Retrieved from www.theijbm.com

Rudhumbu, N. (2014a). Implementation of Talent Management Strategies in Higher Education: Evidence from Botswana. International Journal of Higher Education Management (IJHEM), 1(1), 86-99.

Rudhumbu, N. (2014b). Implementation of Talent Management Strategies in Higher Education: Evidence from Botswana. J Hum Ecol, 1(1), 86-99.

Sonia, C. \& Krishnan, J. (2015). Talent Management in Higher Education Sector. IRACST-International Journal of Research in Management \& Technology (IJRMT), 5(August), 302-311.

Sonia, C., Krishnan, J., \& Joseph 's, S. (2015). Talent Management in Higher Education Sector. IRACSTInternational Journal of Research in Management \& Technology, 5(4), 2249-9563.

Stans, L. (2012). Talent Management and the Cultural Influences on Human Resource Management Processes A comparison on HRM practices between companies from Sweeden and Romania. Thesis, (1981).

Trayek, F. A. A., Tunku Ahmad, T. B., Nordin, M. S., Dwikat, M. A., Abulibdeh, E. S. A., Asmar, M., \& Sawari, S. S. M. (2016). Underlying Structure of E-Learning Readiness among Palestinian Secondary School Teachers. MATEC Web of Conferences, 56, 01011. https://doi.org/10.1051/matecconf/20165601011

Wambui, N. (2012). Talent Management Practices in Commercial State Corporations in KenyaA Research Project Submitted in Partial Fulfilment of the.

Wiktorowicz, J. (2016). Exploratory Factor Analysis in the Measurement of the Competencies of Older People. Ekonometria Econometrics, 4(54). https://doi.org/10.15611/ekt.2016.4.03 